Although the diagnosis of ECD was established in our patient already, the cause of the pericardial effusion was not proved. If this patient were to present with recurrent pericardial effusion despite ongoing appropriate chemotherapy for ECD, a more radical pericardial resection might be indicated because the pericardial histology was consistent with ECD. ${ }^{6}$

In summary, the clinical observation from this case is that ECD, although rare, has important cardiovascular presentations. Cardiac involvement might require surgical intervention. The associated systemic manifestations can complicate perioperative recovery. Successful management depends on taking the diverse clinical manifestations of this multicentric disease into account.

\section{References}

1. Veyssler-Belot C, Cacoub P, Caparros-Lefebvre D, Wechsler J, Brun B, Remy M, et al. Erdheim-Chester disease. Clinical and radiologic characteristics of 59 cases. Medicine (Baltimore). 1996;75:157-69.
2. Gupta A, Kelly B, McGuigan JE. Erdheim-Chester disease with prominent pericardial involvement: clinical, radiologic and histologic findings. Am J Med Sci. 2002;324:96-100.

3. Lachenal F, Cotton F, Desmurs-Clavel H, Haroche J, Taillia H, Magy N, et al. Neurological manifestations and neuroradiological presentation of Erdheim-Chester disease: report of 6 cases and systematic review of the literature. J Neurol. 2006;253:1267-77.

4. Haroche J, Amoura Z, Dion E, Wechsler B, Costedoat-Chalumeau N, Cacoub P, et al. Cardiovascular involvement, an overlooked feature of Erdheim-Chester disease: report of 6 new cases and a literature review. Medicine (Baltimore). 2004;83:371-92.

5. Elgeti T, Schlegl M, Nitardy A, Kivelitz DE, Stockburger M. Images in cardiovascular medicine. Magnetic resonance imaging guiding pacemaker implantation for severe sinus node dysfunction due to cardiac involvement in Erdheim-Chester disease. Circulation. 2007;115: e412-4.

6. Piehler JM, Pluth JR, Schaff HV, Danielson GK, Orszulak TA, Puga FJ. Surgical management of effusive pericardial disease. Influence of extent of pericardial resection on clinical course. J Thorac Cardiovasc Surg. 1985;90:506-16.

\title{
Intraoperative fluorescence angiography to determine the extent of injury after penetrating cardiac trauma
}

\author{
Nimesh D. Desai, MD, ${ }^{a}$ Fuad Moussa, MD, ${ }^{a}$ Steve K. Singh, MD, ${ }^{a}$ Peter Chu, MD, and Stephen E. Fremes, MD, ${ }^{a}$ \\ Toronto, Ontario, Canada
}

$\mathrm{P}$ enetrating cardiac trauma necessitates prompt surgical repair of injuries. We present a case report demonstrating the use of fluorescence coronary angiography to delineate the extent of coronary injury after temporary repair of a penetrating stab wound.

\section{Clinical Summary}

A 22-year old man sustained a knife wound to the left side of his chest and was transported to a quaternary care trauma center with severe shock and hypotension. Precipitous loss of vital signs while in the hospital led to immediate left anterior thoracotomy in the

From the Divisions of Cardiac and Vascular Surgery, ${ }^{\mathrm{a}}$ and General Surgery, ${ }^{\text {b }}$ Sunnybrook Health Sciences Centre, University of Toronto, Toronto, Ontario, Canada.

Received for publication May 12, 2007; accepted for publication May 30, 2007.

Address for reprints: Nimesh D. Desai, MD, Division of Cardiac and Vascular Surgery, Sunnybrook Health Sciences Centre, 2075 Bayview Ave, Room H410, Toronto, Ontario, Canada, M4P 1S7 (E-mail: nimesh.desai@vtoronto. ca).

J Thorac Cardiovasc Surg 2008;136:218-9

$0022-5223 / \$ 34.00$

Copyright $\odot 2008$ by The American Association for Thoracic Surgery doi:10.1016/j.jtcvs.2007.05.073 emergency department, revealing a tense hemopericardium. The pericardium was incised sharply, and a large amount of clot was evacuated. Spontaneous rhythm returned after a brief period of open cardiac massage. Examination of the heart revealed a through-and-through laceration of the right ventricle, with an anterior wall entry wound and posterior wall exit wound. Surgical staples were applied to entry and exit wounds for immediate hemostasis, and the patient was transferred to the operating room for definitive cardiac repair.

Rapid biventricular failure with hemodynamic instability ensued, although a transesophageal echocardiogram revealed no intracardiac injuries. In response to impending circulatory arrest, cardiopulmonary bypass was rapidly initiated. Examination of the posterior wall exit wound during bypass revealed that the surgical staples had occluded the posterior descending coronary artery (PDA). The staples impinging on the PDA were removed. The posterior ventricular laceration was in close proximity to the PDA but did not involve the artery itself. Ventricular repair was completed with pledgeted polypropylene sutures, as illustrated in Figure 1. It was unclear whether the PDA had been significantly damaged by the staples, and coronary artery bypass grafting to the PDA was considered. To delineate the coronary anatomy, intraoperative coronary fluorescence angiography was performed. ${ }^{1,2}$ A bolus of $1 \mathrm{~mL}$ indocyanine green contrast dye was injected into the aortic root through the cardioplegia catheter. As shown in Figure 2, the PDA was widely patent, and excellent perfusion of the posterior wall was 


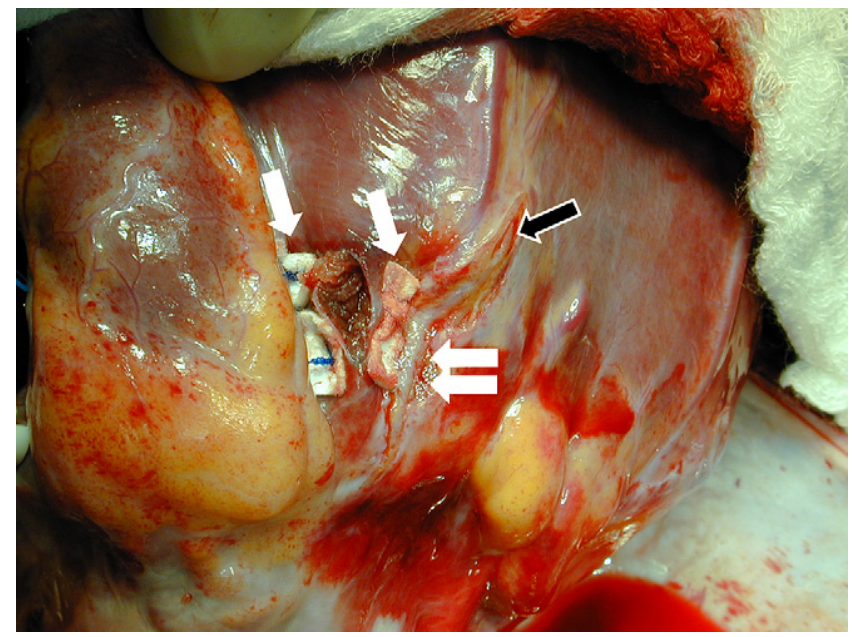

Figure 1. Intraoperative photograph of repaired exit wound in close proximity to posterior descending coronary artery. Single white arrows represent pledgeted ventricular repair sutures. Double white arrow represents area of posterior descending coronary artery entrapped by temporary staples. Black arrow represents ongoing posterior descending coronary artery.

demonstrated. Coronary artery bypass grafting was therefore not performed. The patient was successfully weaned from cardiopulmonary bypass, extubated on the first postoperative day, and discharged home in 7 days with no disability.

\section{Discussion}

Coronary artery injuries, which are infrequent in the setting of penetrating chest trauma, are typically seen with acute pericardial tamponade. The left anterior descending and right coronary arteries are most often involved. Smaller coronary branches may be ligated without major sequelae, but main coronary branches often require bypass grafts. In this case, hemodynamic collapse as a result of biventricular failure after control of the cardiac injuries in the emergency department necessitated institution of cardiopulmonary bypass; however, many such injuries do not require this. ${ }^{3}$ The use of surgical staples in the emergency department has enabled extremely rapid local control of bleeding and is now routine in many centers. ${ }^{4}$ In this case, rather than simply perform a precautionary bypass to the PDA, we opted to define the coronary anatomy by means of intraoperative coronary fluorescence angiography with indocyanine green contrast. This is an emerging method of vascular angiography in which a near-infrared laser excites indocyanine

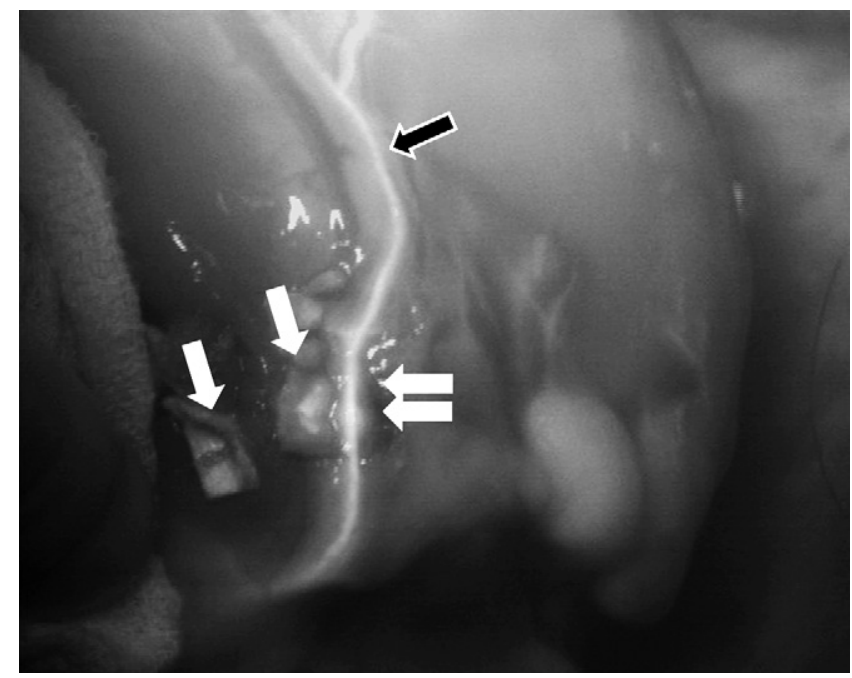

Figure 2. Intraoperative fluorescence angiogram. Single arrows represent pledgeted ventricular repair sutures. Double arrow represents area of posterior descending coronary artery entrapped by temporary staples. Black arrow represents ongoing posterior descending coronary artery illuminated with fluorescent contrast dye.

green dye, causing fluorescence that can be seen in real time on a digital monitor. ${ }^{1,2}$ It is most frequently used to determine the intraoperative patency of coronary artery bypass grafts. This report demonstrates the clinical utility of image-guided cardiac surgery with fluorescence angiography with indocyanine green contrast in determining the extent of native coronary artery injuries in the setting of acute trauma.

\section{References}

1. Taggart DP, Choudhary B, Anastasiadis K, Abu-Omar Y, Balacumaraswami L, Pigott DW. Preliminary experience with a novel intraoperative fluorescence imaging technique to evaluate the patency of bypass grafts in total arterial revascularization. Ann Thorac Surg. 2003;75:870-3.

2. Desai ND, Miwa S, Kodama D, Cohen G, Christakis GT, Goldman BS, et al. Improving the quality of coronary bypass surgery with intraoperative angiography: validation of a new technique. $\mathrm{J}$ Am Coll Cardiol. 2005;46:1521-5.

3. Reissman P, Rivkind A, Jurim O, Simon D. Case report: the management of penetrating cardiac trauma with major coronary artery injury-is cardiopulmonary bypass essential? J Trauma. 1992;33:773-5.

4. Shamoun JM, Barraza KR, Jurkovich GJ, Salley RK. In extremis use of staples for cardiorrhaphy in penetrating cardiac trauma: case report. J Trauma. 1989;29:1589-91. 